\title{
Voiding Dysfunction due to Multiple Sclerosis: a Large Scale Retrospective Analysis
}

\author{
Bulent Onal, Aksel Siva, Ibrahim Buldu, Oktay Demirkesen, Bulent Cetinel \\ Departments of Urology (BO, IB, OD, BC) and Neurology (AS), Cerrahpasa School of Medicine, \\ University of Istanbul, Istanbul, Turkey
}

\begin{abstract}
Purpose: To assess the outcome of urologic evaluation in patients with voiding dysfunction due to multiple sclerosis (MS) and to determine the relationship between urological and neurological parameters of these patients.

Materials and Methods: We retrospectively reviewed the medical records of 249 consecutive patients (162 female and 87 male) with MS who were referred to our clinic between 1991 and 2006, with a median time of 4 years (range 3 months to 26 years) of MS onset. Data was analyzed with respect to patient demographics and findings of initial evaluation. Lower urinary tract symptoms were evaluated by Boyarsky symptom index.

Results: All patients except 13 had lower urinary tract symptoms and 70\% manifested mixed symptoms. Total, storage and voiding symptom scores correlated with expanded disability status scale scores $(\mathrm{p}<0.05)$. Twelve patients $(5 \%)$ had abnormal upper urinary tract. Ultrasound findings of lower urinary tract were abnormal in 12 patients $(5 \%)$. No demographic parameters were associated with abnormal findings of upper urinary tract on univariate analysis. Urodynamic evaluation of 75 patients (30.1\%) revealed detrusor overactivity with or without detrusor-sphincter dyssynergia in 56 (75\%). No correlation was found between urodynamic diagnosis and upper tract deterioration and urinary symptom scores $(\mathrm{p}>0.05)$. Conclusions: The prevalence of mixed symptoms in patients with MS is higher than storage or voiding symptoms alone. Although detrusor overactivity and detrusor-sphincter dyssynergia were the most common urodynamic diagnoses, upper urinary tract deterioration was rare in our series.
\end{abstract}

Key words: multiple sclerosis; urodynamics; urination disorders; ultrasound

Int Braz J Urol. 2009; 35: 326-33

\section{INTRODUCTION}

Multiple sclerosis (MS) is a common neurological disease affecting mostly young adults with a prevalence of 50 to $100 / 100,000$ individuals (1). Regionally, the median estimated prevalence of MS is the highest in Europe (80 per 100000 ), followed by the Eastern Mediterranean (14.9), the Americas (8.3), the Western Pacific (5), South-East Asia (2.8) and Africa (0.3) (2). Lower urinary tract symptoms (LUTS) are common and severely disturb patient quality of life
(3). The reported incidence of voiding dysfunction is found in $33-52 \%$ of MS patients sampled consecutively regardless of urinary symptoms and its incidence is related to disability status (3-5). Several investigators have emphasized that the urodynamic assessment is essential for treating voiding dysfunction due to MS (6-9). Moreover, some authors have underlined that urodynamic evaluation should be repeated at regular intervals since the pattern of neurologic pathology and voiding dysfunction could change with time in MS patients. However, other authors have suggested 
that a simple algorithm was sufficient for the initial management of the voiding dysfunction in MS, since upper tract deterioration was rare (10-12).

The available data indicate that the high proportion of the detrusor overactivity with detrusorsphincter dyssynergia (DSD) is not associated with an increased risk for severe upper urinary tract deterioration (5,13-15). Hence, the evaluation and follow-up strategy in MS regarding the voiding dysfunction is still controversial. Furthermore, it was our clinical impression that complex urological investigations and follow-up strategy increased the management cost and had the side effect of increasing patient anxiety.

The aim of this study was to determine the outcome of urological evaluation in patients with voiding dysfunction due to MS referred to our urodynamic unit, and to assess the relationship between urological and disease related parameters including the disease activity, its duration, and expanded disability status scale in these patients.

\section{MATERIALS AND METHODS}

We retrospectively reviewed the medical records of 249 consecutive patients (162 female and 87 male) with MS who had been referred to our urodynamic unit between 1991 and 2006, with a median time of 4 years (range 3 months to 26 years) of MS onset. The interval from the age at diagnosis of MS until the age at last neurourological evaluation was accepted as the disease duration. The clinical and demographic information about the neurological diagnosis, including the MS pattern (primary progressive, relapsing-remitting, or secondary progressive), the date of diagnosis, and score of expanded disability status scale (EDSS) was obtained from the patient records of Neurology Department. On the expanded disability status scale disease severity is scored from 0 to 10 at 0.5 point intervals (16).

The history, physical examination findings, the results of serum creatinine level, urinalysis (urine culture when necessary), urodynamic investigation (cystometry-EMG, uroflowmetry, and post-void residual urine volume determination) and urinary tract ultrasonography findings were recorded from the patient files of the urodynamic unit.
LUTS were evaluated by Boyarsky symptom index. The symptom index score comprises storage $(0-10)$ and voiding symptom index scores (0-12). Total symptom index score was calculated by adding the storage and voiding symptom index scores. The severity of LUTS was further stratified according to the total symptom index score on the questionnaire: mild- score lower than 7; moderate- score 8-14; severe- score 15-22. A nurse from the urodynamic unit helped the patients to fill out the symptom score evaluation form.

Upper urinary tract status was analyzed with respect to patient characteristics including age, gender, disease duration, MS pattern, EDSS score of MS, serum creatinine levels, urodynamic findings, symptom index scores, and post-void residual volume.

Chi-square, Fisher's exact test, Mann-Whitney $\mathrm{U}$, analysis of variance (ANOVA), and Pearson Correlation tests were performed for statistical analysis. The Chi-square test was used except in cases where the expected number of patients in any unit (or category) was less than 5, in which case the Fisher's exact test was used. We used the value of $p<0.05$ as the level of statistical significance.

\section{RESULTS}

The median age of patients during the initial urological evaluation was 38 years (range 8 to 68 years). Patient characteristics are outlined in Table-1. Of the 249 patients, 230 (92.3\%) underwent urinary tract ultrasonography, 198 (79.5\%) completed the Boyarsky symptom index and 75 (30.1\%) were evaluated by urodynamic testing.

Median total, storage and voiding symptom scores in 198 evaluated by Boyarsky symptom score of 249 patients were 5, 3 and 1, respectively. All except 13 patients had LUTS, while 129, 47, and 9 of 185 symptomatic patients manifested mixed, storage, and voiding symptoms, respectively. Total, storage and voiding symptom scores weakly correlated with EDSS scores $(\mathrm{p}<0.05)($ Table-2).

Twelve patients $(5 \%)$ had abnormal upper urinary tract, which were unilateral or bilateral hydronephrosis. Ultrasound findings of lower urinary tract were abnormal in 12 patients (5\%), with thick bladder 
Table 1 - Patient characteristics.

\begin{tabular}{lc}
\hline $\mathrm{N} \quad$ & 249 \\
Gender no. (\%) & \\
$\quad$ Female & $162(65)$ \\
$\quad$ Male & $87(35)$ \\
MS pattern no. (\%) & \\
$\quad$ Primary progressive & $51(20.6)$ \\
Relapsing-remitting & $104(41.7)$ \\
Secondary progressive & $94(37.5)$ \\
Median EDSS score (range) & $5.0(0-9)$ \\
Median disease duration & \\
$\quad$ years (range) & $4(3)$ months - 26 years) \\
Median age of patients during the initial urologic evaluation & \\
$\quad$ years (range) & $38(8-68)$ \\
Median serum creatinine level & \\
mg/dL (range) & $0.8(0.3-2.0)$ \\
LUTS no. (\%) & $185 / 198(93)$ \\
Storage & $47(25)$ \\
Voiding & $9(5)$ \\
Mixed & $129(70)$ \\
Incontinence n (\%) & $160 / 198(81)$ \\
Urge & $149(93)$ \\
Stress & $6(4)$ \\
Mixed & $3(2)$ \\
Total & $1(0.5)$ \\
Enuresis nocturna & $1(0.5)$ \\
Urodynamic diagnosis no. (\%) & \\
Normal & $11(15)$ \\
DO & $26(35)$ \\
DO + DSD & $30(40)$ \\
DHIC & $1(1)$ \\
Poor compliance & $7(9)$ \\
Median post-void residual volume & \\
$\quad$ mL (range) & $40(0-480)$ \\
\hline
\end{tabular}

$M S=$ multiple sclerosis; $E D S S=$ expanded disability status scale; LUTS = lower urinary tract symptoms; DO = detrusor overactivity; DSD = detrusor-sphincter dyssynergia; DHIC = detrusor hyperactivity with impaired contractility.

wall as the most common finding (Table-3). No demographic parameter (age, gender, disease duration, MS pattern, or expanded disability MS status score) was associated with upper urinary tract abnormality on univariate analysis (Table-4). All patients who had unilateral or bilateral hydronephrosis remained stable with conservative management during the follow-up.
Urodynamic study performance rate gradually decreased from $100 \%$ to $13 \%$ during the period studied (Figure-1). Urodynamic evaluation of 75 patients revealed detrusor overactivity in $26(35 \%)$, detrusor overactivity with detrusor-sphincter dyssynergia in $30(40 \%)$, detrusor overactivity with impaired contractility in $1(1 \%)$, a poor compliance bladder in 7 $(9 \%)$ and normal findings in $11(15 \%)$. No correlation 
Table 2 - Mean voiding, storage and total symptom score according to expanded disability status scale (EDSS) score.

\begin{tabular}{lcc}
\hline Symptom Score & \multicolumn{2}{c}{ EDSS Score } \\
& $\mathbf{r}$ & $\mathbf{p}$ Value \\
\hline Voiding & 0.172 & 0.025 \\
Storage & 0.174 & 0.023 \\
Total & 0.212 & 0.006 \\
\hline
\end{tabular}

was found between urodynamic diagnosis and upper urinary tract deterioration $(\mathrm{p}>0.05)($ Table-4).

\section{COMMENTS}

In this series $70 \%$ of MS patients had mixed LUTS and symptom scores were correlated with EDSS score. The rate of upper urinary tract deterioration was low (5\%), and all patients were stable with conservative management. Although urodynamic studies most often revealed LUTS (85\%), no correlation was found between upper tract deterioration and urodynamic abnormality. Since our study was retrospective, it may have limited implications. However, this study at least gives a clear message that prospective randomized studies are strongly needed in order to clarify the initial urologic evaluation, since

Table 3 - The abnormal ultrasound findings of upper and lower urinary tract.

\begin{tabular}{lc}
\hline & $\begin{array}{c}\text { Abnormal Findings } \\
\text { N (\%) }\end{array}$ \\
\hline Upper urinary tract & $12(5.2)$ \\
Unilateral hydronephrosis & $5(2)$ \\
Bilateral hydronephrosis & $6(2.6)$ \\
Non-functional kidney with & $1(0.4)$ \\
contralateral mild & $12(5.2)$ \\
Hydronephrosis & $11(4.7)$ \\
Lower urinary tract & $1(0.5)$ \\
Thick bladder wall & \\
Bladder diverticula &
\end{tabular}

there is no established protocol for this subject in the guidelines. This might lead to a decrease in management cost and patient anxiety.

Our series is fairly typical of those previously reported, with a majority of women, as usually found in MS $(3,5,7,17,18)$. In our series $65 \%$ women and $42 \%$ of patients had a relapsing-remitting pattern of MS. This is quite comparable with the patients reported by Ciancio (68\% women and $41 \%$ relapsing-remitting pattern) (6). This suggests that our findings are typical and likely to be comparable to other authors.

The majority of our patients (185 of 198) had LUTS, since the patients developing urologic complaints during the follow-up in the Neurology Department were referred to our clinic. In our study, the rates of mixed, storage and voiding symptoms were found to be 70,25 , and $5 \%$, respectively. Our results are similar to the reports from Western countries which revealed that storage symptoms such as urgency, frequency were the predominant urinary symptoms in MS $(5,7)$. Araki et al. reported that voiding symptoms were equal to or higher than that of storage symptoms in Japan (19). However, in their study, the proportions of detrusor hyporeflexia and detrusor sphincter dyssynergia were higher than our study and those reported from Western countries.

When evaluating the relationship between neurologic and urologic abnormalities, we found a weak correlation between severity of EDSS and storage, voiding and total symptom scores. In some studies no correlation was found $(20,21)$, whereas in others a direct correlation between EDSS score and storage and/or voiding score was reported $(3,8,22)$. Araki et al. found that storage symptoms correlated well with expanded disability status scale scores but voiding symptoms did not. Variability in the correlation probably relates to the clinical course of MS which is characterized by exacerbations and remissions.

Multiple sclerosis is a disease with frequent presentation of LUTS whereas upper tract deterioration is rare. Many other studies including ours also showed that progression to upper tract deterioration in MS was usually the exception rather than the rule $(1,5,12,23)$. In the current series $5 \%$ of the patients had upper tract deterioration, although mild hydronephro- 
Table 4 - The relationship of abnormal findings of upper urinary tract (UUT) with respect to patient characteristics.

\begin{tabular}{|c|c|c|c|c|}
\hline & & Abnormal UUT & Normal UUT & p Value \\
\hline No. of the patients & $\mathrm{N}(\%)$ & $12(5.2)$ & $218(94.8)$ & \\
\hline Gender & $\mathrm{N}(\%)$ & & & \\
\hline Female & & $9(6)$ & $142(94)$ & 0.756 \\
\hline Male & & $3(4)$ & $76(96)$ & \\
\hline MS pattern & $\mathrm{N}(\%)$ & & & \\
\hline \multicolumn{2}{|c|}{ Primary progressive (PP) } & $1(2)$ & $47(98)$ & $0.663 *$ \\
\hline \multicolumn{2}{|c|}{ Relapsing-remitting (RR) } & $4(4)$ & $90(96)$ & $0.260 * *$ \\
\hline \multicolumn{2}{|c|}{ Secondary progressive (SP) } & $7(8)$ & $81(92)$ & \\
\hline \multicolumn{2}{|c|}{$\begin{array}{l}\text { Median EDSS score } \\
\quad \text { (range) }\end{array}$} & $\begin{array}{c}5.3 \\
(3-9)\end{array}$ & $\begin{array}{l}5.0 \\
(0-9)\end{array}$ & 0.230 \\
\hline \multicolumn{4}{|l|}{ Median disease duration } & 0.410 \\
\hline \multicolumn{4}{|c|}{ Median age of patients during the initial urologic evaluation } & 0.884 \\
\hline $\begin{array}{l}\text { LUTS } \\
\text { Storage } \\
\text { Voiding } \\
\text { Mixed }\end{array}$ & $\mathrm{N}(\%)$ & $\begin{array}{l}12 \\
4(9) \\
- \\
8(7)\end{array}$ & $\begin{array}{l}160 \\
39(91) \\
8(100) \\
113(93)\end{array}$ & 0.612 \\
\hline $\begin{array}{l}\text { Incontinence } \\
\text { Urge } \\
\text { Stress } \\
\text { Mixed } \\
\text { Total } \\
\text { Enuresis nocturna }\end{array}$ & $\mathrm{N}(\%)$ & $\begin{array}{l}10 \\
10(7) \\
- \\
- \\
- \\
-\end{array}$ & $\begin{array}{r}150 \\
139(93) \\
6(100) \\
3(100) \\
1(100) \\
1(100)\end{array}$ & NA \\
\hline $\begin{array}{l}\text { Lower urinary tract sta } \\
\text { Normal } \\
\text { Abnormal }\end{array}$ & & $\begin{array}{l}10(5) \\
2(17)\end{array}$ & $\begin{array}{r}208(95) \\
10(83)\end{array}$ & 0.123 \\
\hline $\begin{array}{l}\text { Urodynamic diagnosis } \\
\text { Normal } \\
\text { DO } \\
\text { DO + DSD } \\
\text { DHIC } \\
\text { Poor compliance }\end{array}$ & N (\%) & $\begin{array}{l}12 \\
4(36) \\
2(8) \\
3(10) \\
1(100) \\
2(29)\end{array}$ & $\begin{array}{l}63 \\
7(64) \\
24(92) \\
27(90) \\
-(-) \\
5(71)\end{array}$ & $0.068 * * *$ \\
\hline Median post-void resic & lal volume mL (range) & $147(0-480)$ & $40(0-430)$ & 0.223 \\
\hline
\end{tabular}

$M S=$ multiple sclerosis; EDSS = expanded disability status scale; LUTS = lower urinary tract symptoms; DO = detrusor overactivity; $D S D=$ detrusor-sphincter dyssynergia; DHIC = detrusor hyperactivity with impaired contractility. * PP versus RR; ** PP versus SP; *** Urodynamic diagnosis was classified as normal or high pressure for statistical analysis.

sis was present in all except one patient. Koldewijn et al. reviewed $14 \mathrm{MS}$ series of 2,076 patients regarding upper tract deterioration and found its incidence to be as low as $0.34 \%(5)$.
Meta analysis of 1,882 patients showed that abnormal urodynamic findings in MS patients with LUTS were common whereas neurogenic detrusor overactivity and detrusor sphincter dyssynergia being 


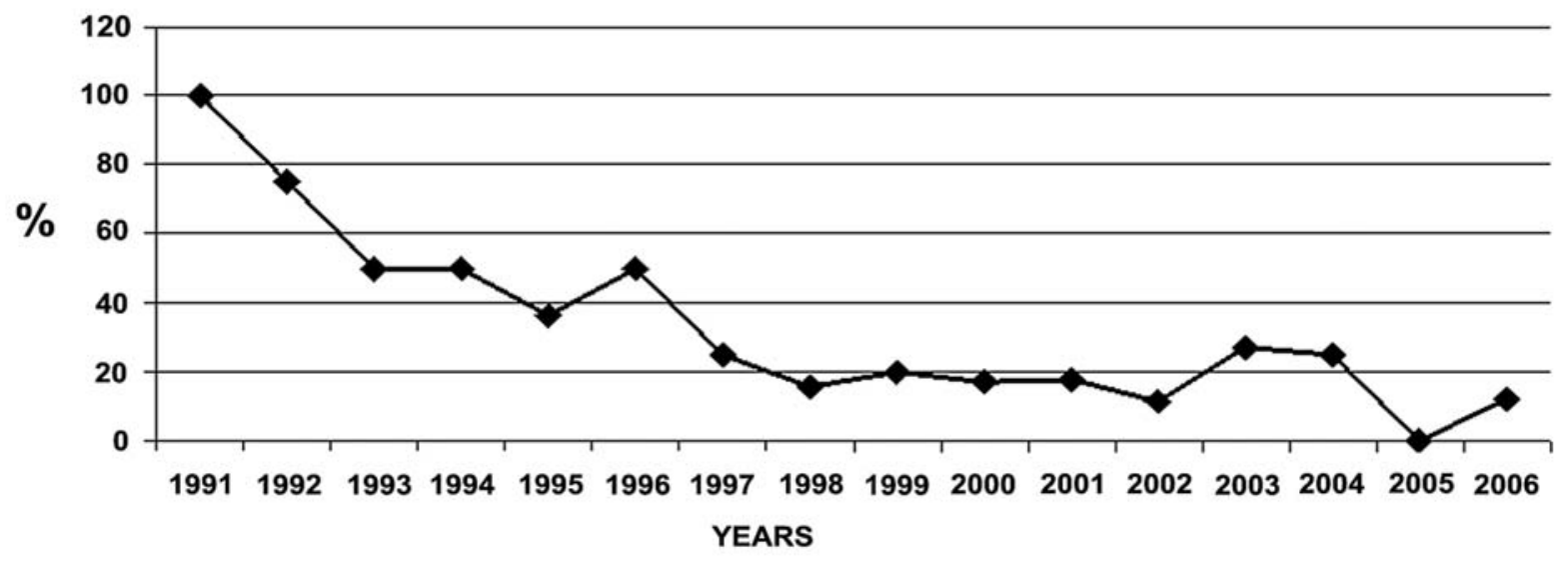

Figure 1 - The rate of the urodynamic study with respect to years.

the most common $(10,23)$. In contrast to detrusor sphincter dyssynergia in spinal cord injury, DSD in MS patients are rarely associated with upper tract deterioration while the reason for this is unclear $(5,23$ 26). It has been speculated that possibility of poorly sustained detrusor contractions and less severe degree of DSD in MS could be responsible for this distinction $(23,27)$. Detrusor overactivity and detrusor sphincter dyssynergia were the most common urodynamic diagnoses in our study as in the previous studies, and also no urodynamic finding was determined to be a risk factor for upper tract deterioration as in the study of Litwiller et al. (23).

Not surprisingly, we found no association between the high proportion of detrusor overactivity/detrusor-sphincter dyssynergia and incidence of upper urinary tract abnormalities. Lemack et al. investigated the risk factors for deterioration of upper tract and showed that no disease related or urodynamic parameters were predictive of abnormalities on renal ultrasonography. In addition, no patients in their series had any indication of obstructive uropathy more severe than mild hydronephrosis (18). Our findings agree with this stance in that only one of our patients had unilateral non-functional kidney. Moreover, our ratio of upper tract deterioration was found to be low and comparable to those in other series, which ranged between $0-25 \%(5,14,18,23,28)$. In a recent study done by Lemack et al. these authors compared the detrusor pressures between MS patients with and without DSD and observed non-significant elevations in detrusor pressures in both groups. This finding could explain the relatively low incidence of upper tract damage in patients with MS (15).

Our urodynamic study performance rate gradually decreased from $100 \%$ to $13 \%$ during the study period. Although our data is far from providing strong evidence for the overuse of urodynamic studies during initial urologic evaluation of MS patients, on the basis of the literature mentioned above and our increasing experience with MS patients this suggests that the multichannel urodynamic studies might be used only in the evaluation of patients with upper tract deterioration or with conservative treatment failure. We believe that this policy might lead to a decrease in the management cost and patient anxiety.

A weakness of our study was that our data was collected retrospectively. However, the literature is fully supportive of our local data. Another potential weakness of our study is that we were not able to use a unique protocol for initial urologic evaluation of these patients, since there is no previously established protocol for this subject in the guidelines. Despite these limitations, we believe that our results provide a useful insight for clinicians when counseling patients with MS. 


\section{CONCLUSIONS}

The prevalence of mixed symptoms in patients with MS is higher than storage or voiding symptoms alone. Although detrusor overactivity and detrusor-sphincter dyssynergia were the most common urodynamic diagnoses, upper urinary tract deterioration was rare in this series. Prospective randomized studies are needed to clarify initial urologic evaluation for MS patients.

\section{CONFLICT OF INTEREST}

None declared.

\section{REFERENCES}

1. Hinson JL, Boone TB: Urodynamics and multiple sclerosis. Urol Clin North Am. 1996; 23: 475-81.

2. World Health Organization and Multiple Sclerosis International Federation: Atlas. Multiple Sclerosis Resources in the World 2008. Thônex, CH, Tushita Graphic Vision. 2008.

3. Araki I, Matsui M, Ozawa K, Takeda M, Kuno S: Relationship of bladder dysfunction to lesion site in multiple sclerosis. J Urol. 2003; 169: 1384-7.

4. Bemelmans BL, Hommes OR, Van Kerrebroeck PE, Lemmens WA, Doesburg WH, Debruyne FM: Evidence for early lower urinary tract dysfunction in clinically silent multiple sclerosis. J Urol. 1991; 145: 1219-24.

5. Koldewijn EL, Hommes OR, Lemmens WA, Debruyne FM, van Kerrebroeck PE: Relationship between lower urinary tract abnormalities and disease-related parameters in multiple sclerosis. J Urol. 1995; 154: $169-73$.

6. Ciancio SJ, Mutchnik SE, Rivera VM, Boone TB: Urodynamic pattern changes in multiple sclerosis. Urology. 2001; 57: 239-45.

7. Gallien P, Robineau S, Nicolas B, Le Bot MP, Brissot $\mathrm{R}$, Verin M: Vesicourethral dysfunction and urodynamic findings in multiple sclerosis: a study of 149 cases. Arch Phys Med Rehabil. 1998; 79: 255-7.

8. Giannantoni A, Scivoletto G, Di Stasi SM, Grasso MG, Finazzi Agrò E, Collura G, et al.: Lower urinary tract dysfunction and disability status in patients with multiple sclerosis. Arch Phys Med Rehabil. 1999; 80: 437-41.
9. McGuire EJ, Savastano JA: Urodynamic findings and long-term outcome management of patients with multiple sclerosis-induced lower urinary tract dysfunction. J Urol. 1984; 132: 713-5.

10. Kalsi V, Fowler CJ: Therapy Insight: bladder dysfunction associated with multiple sclerosis. Nat Clin Pract Urol. 2005; 2: 492-501.

11. Kornhuber HH, Schütz A: Efficient treatment of neurogenic bladder disorders in multiple sclerosis with initial intermittent catheterization and ultrasound-controlled training. Eur Neurol. 1990; 30: 260-7.

12. Sirls LT, Zimmern PE, Leach GE: Role of limited evaluation and aggressive medical management in multiple sclerosis: a review of 113 patients. J Urol. 1994; 151: 946-50.

13. Kasabian NG, Krause I, Brown WE, Khan Z, Nagler HM: Fate of the upper urinary tract in multiple sclerosis. Neurourol Urodyn. 1995; 14: 81-5.

14. Krhut J, Hradílek P, Zapletalová O: Analysis of the upper urinary tract function in multiple sclerosis patients. Acta Neurol Scand. 2008; 118: 115-9.

15. Lemack GE, Frohman E, Ramnarayan P: Women with voiding dysfunction secondary to bladder outlet dyssynergia in the setting of multiple sclerosis do not demonstrate significantly elevated intravesical pressures. Urology. 2007; 69: 893-7.

16. Kurtzke JF: Rating neurologic impairment in multiple sclerosis: an expanded disability status scale (EDSS). Neurology. 1983; 33: 1444-52.

17. Barbalias GA, Nikiforidis G, Liatsikos EN: Vesicourethral dysfunction associated with multiple sclerosis: clinical and urodynamic perspectives. J Urol. 1998; 160: 106-11.

18. Lemack GE, Hawker K, Frohman E: Incidence of upper tract abnormalities in patients with neurovesical dysfunction secondary to multiple sclerosis: analysis of risk factors at initial urologic evaluation. Urology. 2005; 65: 854-7.

19. Araki I, Matsui M, Ozawa K, Nishimura M, Kuno S, Saida T: Relationship between urinary symptoms and disease-related parameters in multiple sclerosis. J Neurol. 2002; 249: 1010-5.

20. Goldstein I, Siroky MB, Sax DS, Krane RJ: Neurourologic abnormalities in multiple sclerosis. J Urol. 1982; 128: 541-5.

21. Miller H, Simpson CA, Yeates WK: Bladder dysfunction in multiple sclerosis. Br Med J. 1965; 1: 12659.

22. McDougall AJ, McLeod JG: Autonomic nervous system function in multiple sclerosis. J Neurol Sci. 2003; 215: 79-85. 


\section{Voiding Dysfunction in Multiple Sclerosis}

23. Litwiller SE, Frohman EM, Zimmern PE: Multiple sclerosis and the urologist. J Urol. 1999; 161: 743-57. Erratum in: J Urol. 1999; 162: 172.

24. Ozkan B, Demirkesen O, Durak H, Uygun N, Ismailoglu V, Cetinel B: Which factors predict upper urinary tract deterioration in overactive neurogenic bladder dysfunction? Urology. 2005; 66: 99-104.

25. Wein AJ: Editorial comment on "Incidence of upper tract abnormalities in patients with neurovesical dysfunction secondary to multiple sclerosis: Analysis of risk factors at initial urologic evaluation. Urology, 65: 854-857, 2005”. J Urol. 2006; 175: 1030.

26. Wyndale JJ, Castro D, Madersbacher H: Neurogenic and Faecal Incontinence. Plymouth, England, Health Publication Ltd. 2005; pp. 1059-62

27. Gonor SE, Carroll DJ, Metcalfe JB: Vesical dysfunction in multiple sclerosis. Urology. 1985; 25: 429-31.

28. Andersen JT, Bradley WE: Abnormalities of detrusor and sphincter function in multiple sclerosis. Br J Urol. 1976; 48: 193-8.

\section{Correspondence address:}

Dr. Bulent Onal

Urology Department

Cerrahpasa School of Medicine

Istanbul University

Fatih, Istanbul, 34730, Turkey

E-mail: bulonal@yahoo.com 